\title{
PPGLinC 110
}

\section{ANOS DO PPGLinC - OS EGRESSOS EM FOCO: UMA APRESENTAÇÃO}

10 YEARS OF PPGLinC - ALUMNI IN FOCUS: A PRESENTATION

Silvana Soares Costa Ribeiro 1 Universidade Federal da Bahia Cristina Figueiredo ${ }^{2}$ Universidade Federal da Bahia Marcela Moura Torres Paim ${ }^{3}$ Universidade Federal Rural de Pernambuco

Valter Pereira Romano Universidade Federal de Santa Catarina

\section{CELEBRAR O CONHECIMENTO E A VIDA}

Para comemorar os 10 anos de criação do Programa de Pós-Graduação em Língua e Cultura da Universidade Federal da Bahia, doravante PPGLinC, no ano de 2020, o Colegiado do Programa realizou uma série de ações acadêmicas para marcar a data. Dentre elas lançou editais, incentivando a publicação de trabalhos

\footnotetext{
silvanar@ufba.br

macrisfig@uol.com.br

3 marcela.paim@ufrpe.br

4 valter.pereira.romano@gmail.com
}

1 № 68, NÚM. ESP.|2020, Salvador: pp. 1-23 
de discentes de Mestrado e Doutorado, que culminaram com a produção de uma obra em dois volumes, intitulados: Volume 1, Língua em Movimento: História e funcionamento das línguas naturais, e Volume 2, Lingua em Movimento: Estudos em linguagem e interação ${ }^{6}$, totalizando 42 artigos, cuja autoria principal é de um discente do programa; organizou o I Fórum de Autoavaliação e Planejamento Estratégico do PPGLinC (conduzido pela Comissão de Avaliação e Planejamento Estratégico) e promoveu o Seminário Comemorativo PPGLinC 10 anos que ocorreu em dezembro de 2020, em conjunto com o Seminário Estudantil de Pesquisa (SEPESQ)7, evento que congrega alunos de Graduação e Pós-Graduação do Instituto de Letras da UFBA.

Como outra ação comemorativa, visando convidar para a festa do conhecimento os egressos do PPGLinC, sugeriu-se aos editores da Revista Estudos Linguísticos e Literários $^{8}$ que avaliassem a possibilidade de organização de um Dossiê da Revista ELL, ou de um número especial na edição da Revista do $2^{\text {o }}$ semestre de 2020, dedicado à divulgação de artigos de egressos do PPGLinC. Coube a duas docentes da UFBA e a dois outros colegas de instituições de ensino superior do Brasil (UFRPE e UFSC) ${ }^{9}$ a tarefa da organização do Dossiê.

\footnotetext{
5 As obras foram produzidas no contexto do UFBA em Movimento. Evento iniciado a partir da publicação da Portaria 103/2020 (UFBA), que determinava o distanciamento físico e promovia mudanças na rotina acadêmica da Universidade, e da idealização em abril de 2020 e realização, em maio de 2020, do Congresso UFBA Virtual 2020. Buscavam-se, dentre outros objetivos, manter a comunidade produtiva, viva e engajada nas ações de continuidade das atividades de Ensino, Pesquisa e Extensão. Para mais informações consultem os sites dos eventos disponíveis em: https://ufbaemmovimento.ufba.br/ e https://congresso2020.ufba.br/.

6 Volume 1. Disponível em: < http://repositorio.ufba.br/ri/handle/ri/32460>. Volume 2.

Disponível em: <http://repositorio.ufba.br/ri/handle/ri/32459>.

7 Maiores informações sobre o Seminário Comemorativo PPGLinC 10 anos e o Seminário

Estudantil de Pesquisa (SEPESQ) estão disponíveis em: http://www.sepesq2020.ufba.br/.

8 Revista dos Programas de Pós-Graduação do Instituto de Letras da Universidade Federal da Bahia: (i) Programa de Pós-Graduação em Língua e Cultura - PPGLinC e (ii) Programa de PósGraduação em Literatura e Cultura - PPGLitCult.

9 Silvana Ribeiro (UFBA), egressa do curso de Mestrado em Letras e do Programa de PósGraduação Letras e Linguística (PPGLL), DO; Cristina Figueiredo (UFBA), egressa do Programa de Pós-Graduação em Língua e Cultura (PPGLinC), ME e DO; Marcela Paim (UFRPE), egressa do PPGLL, ME e DO, e Valter Romano (UFSC), egresso do Programa de Pós-Graduação em Estudos de Linguagem (PPGEL), ME e DO.
} 
Um dos objetivos do então Dossiê, além de celebrar os 10 anos de criação do PPGLinC, era o de dar visibilidade e destaque às pesquisas realizadas pelos egressos do Programa, abarcando os diversos aspectos linguísticos e culturais que caracterizam as linhas de pesquisa em que são desenvolvidas.

A chamada para submissão de artigos, realizada no período de 11 de agosto a 4 de outubro de 2020, enfatizava que os trabalhos elaborados pelos egressos poderiam contemplar temas desenvolvidos durante o curso de Mestrado e de Doutorado, bem como outros resultantes de pesquisa realizada em suas vidas acadêmicas após a formação no PPGLinC, revelando os perfis de atuação dos egressos.

Dessa forma, os ex-alunos do PPGLinC foram incentivados a submeter artigos para o Dossiê, inclusive aqueles que cursaram o DINTER/ PPGLL/ UFBA/ UNIOESTE/ Cascavel10, os quais concluíram seus cursos e se pós-graduaram pelo PPGLinC. A chamada previa ainda que o egresso estivesse vinculado a uma instituição de ensino em qualquer nível ou realizando atividade profissional referente à pesquisa desenvolvida no PPGLinC. O Dossiê foi, posteriormente, convertido em Volume Especial Comemorativo 10 anos do PPGLinC - egressos (no 68/2020), tendo em vista o significativo número de trabalhos submetidos à Revista ELL.

O aluno egresso de Doutorado do PPGLinC deveria ser o autor principal do artigo em casos de coautoria. Caso o artigo fosse originado de egresso do curso de Mestrado, sugeria-se, preferencialmente, que a escrita fosse realizada em coautoria com um(a) pesquisador(a) doutor(a).

Complementarmente e visando à identificação dos perfis formativos dos autores e, sobretudo, a importância do PPGLinC em suas trajetórias acadêmicas, solicitou-se aos proponentes de artigos que fossem formuladas minibiografia(s)

10 Doutorado Interinstitucional celebrado entre a UFBA e a UNIOESTE/Cascavel, originado no Programa de Pós-Graduação em Letras e Linguística (PPGLL). 
do(s) autor(es) registrando a importância do PPGLinC para sua(s) vida(s) acadêmica(s) e profissional(is). Os textos enviados pelos autores selecionados estão publicados após as referências bibliográficas e intitulados: “O autor e o PPGLinC".

Do ponto de vista histórico, o PPGLinC/UFBA resulta do desmembramento do Programa de Pós-Graduação em Letras e Linguística (PPGLL), cujas atividades foram iniciadas em 1996, ampliando o primeiro Curso de Mestrado da UFBA, fundado em 1976. Tal desmembramento foi motivado por sugestões avaliativas da CAPES, as quais indicavam a premência de atender às mudanças nos paradigmas referentes aos estudos da linguagem, impostas pela necessidade de formação de recursos humanos qualificados no campo dos estudos da linguagem, que requerem perfis interdisciplinares e interculturais, no contexto regional. ${ }^{11}$

Após tramitar nos órgãos acadêmicos internos da UFBA, receber aprovação de reformulação curricular e autorização de funcionamento, e externos a ela, como a CAPES, o PPGLinC iniciou suas atividades em 2010. Foi recomendado à época com nota $5^{12}$. Na avaliação do último Quadriênio (20132016), o PPGLinC obteve a nota 4. Destaca-se que o Programa tem idealizado e implementado um conjunto de ações visando à melhoria da avaliação a cada Quadriênio.

11 O PPGLL foi desmembrado em dois Programas de Pós-Graduação distintos e sediados no Instituto de Letras (ILUFBA): (i) Programa de Pós-Graduação em Língua e Cultura - PPGLinC e (ii) Programa de Pós-Graduação em Literatura e Cultura - PPGLitCult. O Instituto de Letras, atualmente, além do PPGLinC e do PPGLitCult, também agrega o Mestrado Profissional em Letras - Rede Nacional - PROFLETRAS.

12 Parecer aprovado na 112 ${ }^{\mathrm{a}}$ Reunião do Conselho Técnico-Científico da Educação Superior (CTC-ES), em 2 de outubro de 2009. 
Ao iniciar suas atividades, o PPGLinC passou a administrar academicamente, até 2014, o alunado residual do PPGLL, responsabilizando-se pelos discentes com pesquisa em língua e cultura. Como, a partir de 2010, o PPGLL não recebeu mais alunos novos, os alunos do DINTER UFBA/UNIOESTE, convênio firmado com o antigo Programa, foram cadastrados no novo programa. Dessa forma, os egressos do DINTER são os primeiros doutorandos do PPGLinC, motivo pelo qual foram incentivados a participar da chamada para publicação no Volume Especial Comemorativo 10 anos do PPGLinC - egressos, como anteriormente exposto.

Ainda situando o Programa numa perspectiva histórica, podemos marcar as características estruturais de seus currículos em dois momentos: (i) currículo vigente de 2010 até 2018 e (ii) currículo vigente a partir de 2019, com proposta originada de ampla reforma acadêmica e curricular, motivada também por sugestões explicitadas na avaliação quadrienal 2013-2016.

Até 2018, o PPGLinC se organizou em duas áreas e sete linhas de pesquisa ao todo, como a seguir se explicita: Área I - Linguística Histórica, com quatro linhas: (i) Constituição Histórica do Português e das demais Línguas Românicas; (ii) Filologia Textual; (iii) História da Cultura Escrita no Brasil e (iv) Variação da Língua Portuguesa e Teoria da Gramática e Área II - Línguas, Linguagens e Culturas Contemporâneas, constituída por três linhas: (i) Aquisição, Ensino e Aprendizagem de Línguas; (ii) Estudos de Tradução Audiovisual e Acessibilidade e (iii) Texto, Discurso e Cultura.

A partir de 2019, a estrutura curricular vigente no PPGLinC contempla duas áreas subdivididas em três linhas de pesquisa cada uma. A Área I - História e Funcionamento das Línguas Naturais - está organizada com as linhas: (i) Linguística Histórica, Filologia e História da Cultura Escrita, (ii) Dialetologia e Sociolinguística e (iii) Teoria da Gramática. Já a Área II - Linguagem e Interação 
- está subdividida nas linhas: (i) Aquisição de Línguas, Tradução e Acessibilidade, (ii) Linguagem, Cognição e Discurso e (iii) Linguística Aplicada.

\section{A MISSÃO DO PROGRAMA E SEUS EGRESSOS}

Baseada na premissa de realização de um ensino público e de qualidade, a Missão do PPGLinC é a de:

produzir e disseminar conhecimento atual e de qualidade em diferentes domínios de Linguística, Língua e Cultura, com foco na formação e qualificação de profissionais capacitados para enfrentar os desafios e demandas sociais, políticas e econômicas das sociedades contemporâneas, principalmente na docência no nível universitário e na educação básica, bem como em pesquisa científica teórica e/ou aplicada. (PPGLINC, 2021)

Tomando como ponto de partida essa Missão, entendemos que para avaliar o seu cumprimento é importante realizar a pesquisa com os egressos, item também considerado na Avaliação CAPES. Ao ser calculado o índice $\mathrm{H}_{2}{ }^{13}$ de Avaliação Quadrienal CAPES, levam-se em consideração os discentes ativos, os docentes que atuam no Programa e o desempenho dos egressos originados dos cursos.

Nesse sentido, ao realizar a pesquisa de acompanhamento de egressos, observou-se que o número total de egressos do PPGLinC é de 307, sendo 199 profissionais com o título de Mestre e 108 com o título de Doutor. Do total de egressos, 168 estão atuando em universidades brasileiras ou em institutos federais de educação, 58 na educação básica e 13 em instituições de ensino de língua estrangeira e/ou de português como língua estrangeira.

13 Para maiores informações sobre Índice $\mathrm{H}$, consultar o Portal periódicos da CAPES. Disponível em: <https://www-periodicos-capes-govbr.ezl.periodicos.capes.gov.br/index.php?option=com_pnews\&component=Clipping\&view=pne wsclipping\&cid=970\&mn=0\&>. Acesso em: 17 abr. 2021. 
De acordo com o Relatório de Avaliação do PPGLinC 2019, doravante Relatório 2019, enviado ao Coleta CAPES (Plataforma Sucupira) em 2020, nos últimos 5 anos (2015-2019), o Programa formou 123 Mestres e 75 Doutores, o que totaliza 198 pós-graduados no período. O Programa efetua a pesquisa de acompanhamento de egressos, principalmente a partir da consulta ao Currículo Lattes dos ex-discentes.

Como demonstram os dados que a seguir explicitamos, e ainda com base no Relatório 2019, os egressos de Mestrado e Doutorado do PPGLinC podem ser distribuídos por diversas categorias de atuação profissional, fotografando a capilaridade da educação no Estado (pública e privada) e no Nordeste brasileiro. O Gráfico 1 informa os dados dos egressos do curso de Mestrado e o Gráfico 2 dos de Doutorado.

Gráfico 1: Egressos de Mestrado do PPGLinC (2015-2019) - atuação

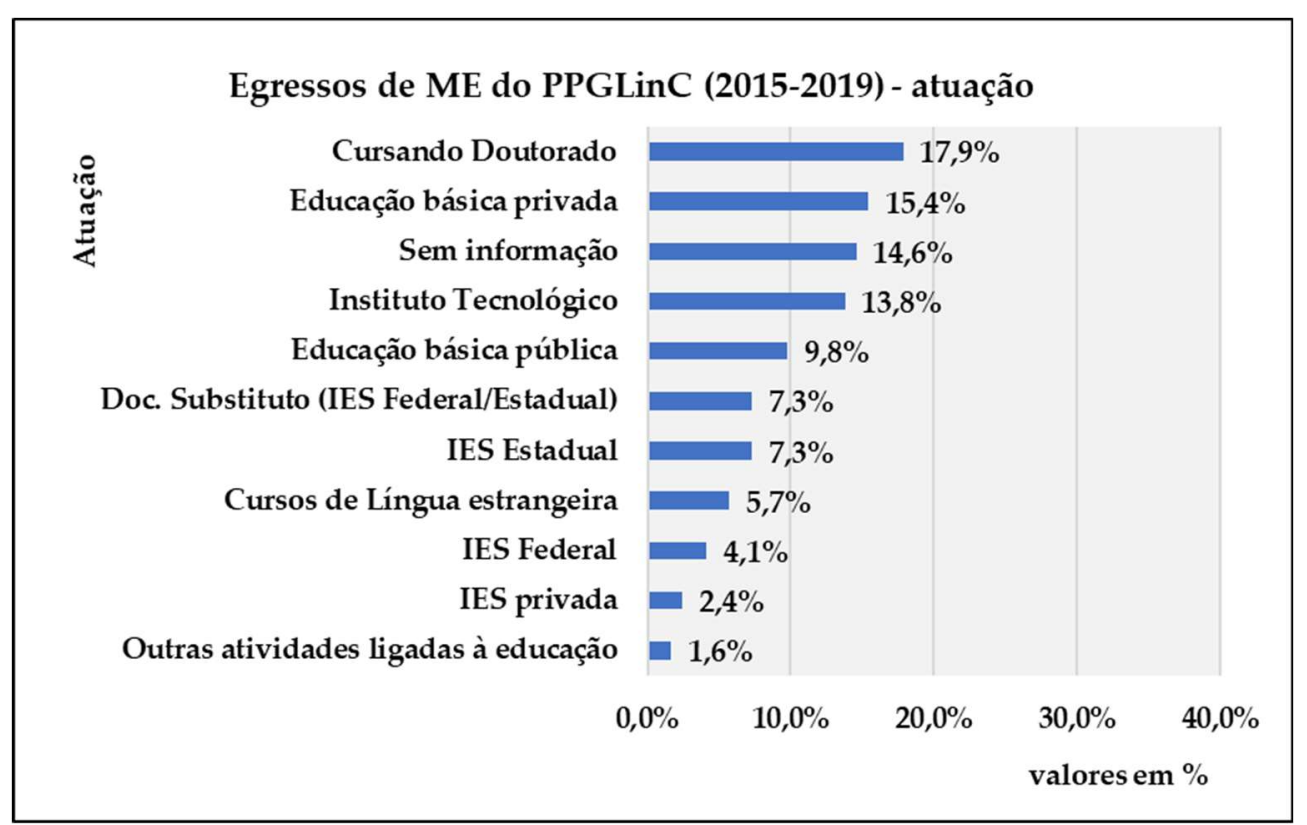

Fonte: Elaborado pelos autores com base em Relatório de Avaliação do PPGLinC 2019 enviado ao Coleta CAPES (Plataforma Sucupira), em 2020 
Gráfico 2: Egressos de Doutorado do PPGLinC (2015-2019) - atuação

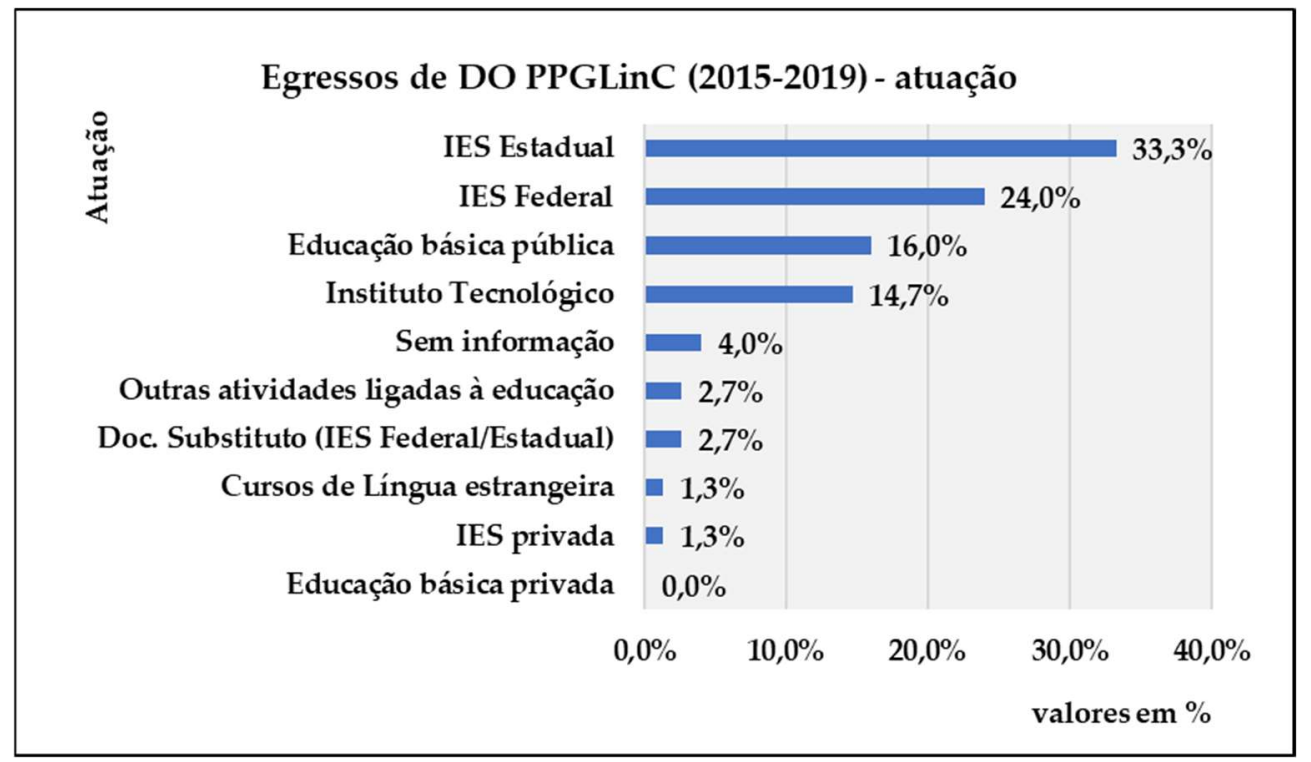

Fonte: Elaborado pelos autores com base em Relatório de Avaliação do PPGLinC 2019 enviado ao Coleta CAPES (Plataforma Sucupira), em 2020

Os resultados obtidos e considerados no último Relatório 2019 demonstram que: (i) os egressos do curso de Mestrado estão atuando no mercado de trabalho e também optando por dar continuidade à formação em PósGraduação, visto que 17,9\% deles estão matriculados em curso de Doutorado e (ii) os egressos do curso de Doutorado, cumprindo a Missão do PPGLinC, estão envolvidos na docência em nível superior, vinculados às Instituições de Ensino Superior (IES), tanto da rede pública (Estadual, 33,3\%, e Federal, 24,0\%) quanto da rede privada (1,3\%), totalizando 58,6\%, e aos Institutos Tecnológicos (14,7\%), e na educação básica (16,0\% somando-se rede pública). Os egressos, agora docentes, contribuem, dessa forma, para a promoção da qualidade de formação dos alunos por eles formados nos níveis fundamental, médio e universitário.

Os dados aqui expostos, além de se alinharem com a Missão do PPGLinC, demonstram também o cumprimento de alguns dos seus objetivos, dos quais destacamos o terceiro e o quarto: 
$3^{\text {o }}$ - Apoiar a capacitação dos pós-graduandos para a pesquisa e para os diferentes níveis de ensino e de extensão, a partir de enfoques diferenciados, dentro das especialidades da área de Letras e Linguística, na interface com a cultura;

4ำ - Ampliar, cada vez mais, o escopo de pesquisa e a produção de conhecimento na área da linguagem, fortalecendo a qualificação dos egressos do programa, capacitando-os como multiplicadores na produção acadêmica nos seus locais de atuação profissional. (PPGLINC, 2021)

Em suma, o PPGLinC, atendendo ao seu terceiro objetivo, com enfoques diversos, contemplando as áreas de Letras e Linguística e focalizando a interface entre Língua e Cultura, vem apoiando “a capacitação dos pós-graduandos para a pesquisa e para os diferentes níveis de ensino e de extensão" (PPGLinC, 2021) como demonstram os números expostos anteriormente e a presença dos egressos dos cursos de Mestrado e Doutorado nas diversas esferas educacionais.

No que se refere à qualificação de pessoal, alinhando-se ao seu quarto objetivo, observamos que os egressos dos cursos de Mestrado do PPGLinC e dos outros implantados no Estado da Bahia e fora dele buscam o Programa como opção para a continuidade da formação acadêmica. Dessa forma, o PPGLinC fortalece “a qualificação dos egressos do programa, capacitando-os como multiplicadores na produção acadêmica nos seus locais de atuação profissional" (PPGLinC, 2021).

No momento em que nosso Programa completa uma década de existência, cabe aqui destacar que um dos egressos de 2013, José Amarante Santos Sobrinho, atualmente docente permanente do PPGLinC e do PPGLitCult, teve a sua tese agraciada com o Prêmio CAPES de Teses - Edição 2014 (Letras e Linguística) e com o Prêmio ANPOLL Teses - Edição 2014 (Menção honrosa).

Sobre a qualidade formativa dos egressos do Programa, o número considerável de artigos publicados em periódicos nacionais vem revelando os frutos colhidos a partir das dissertações de Mestrado e teses de Doutorado defendidas. A chamada da Revista ELL para submissão de artigos ao Volume 
Especial Comemorativo 10 anos do PPGLinC - egressos revela muito bem tal qualidade, como na sequência desta Apresentação se demonstra.

Em resposta à Chamada da Revista ELL, foram recebidos 37 artigos de egressos e um de docente convidada, os quais passaram pela avaliação às cegas por pares. Chegamos, dessa forma, a um total de 29 artigos selecionados, escritos por 41 autores diferentes, sendo 32 de egressos do PPGLinC. Sobre o perfil dos autores dos artigos que compõem o Volume Especial (nº 68/2020), o Quadro 1 sintetiza as características dos artigos e cabe registrar que:

a) duas autoras, Waleska Oliveira Moura (ME/2011) e Edileide da Silva Reis do Carmo (ME/2012), são egressas da primeira turma de mestrandas formadas pelo PPGLinC, vinculadas à Área 2 e à nova linha de pesquisa (Linguística Aplicada), as quais continuam atuando em projetos de pesquisa dentro de suas áreas de formação.

b) duas autoras, Clarice Cristina Corbari (DO/2013) e Any Lamb Fenner (DO/2013), eram discentes da Área 1, vinculadas ao DINTER, Doutorado Interinstitucional entre a UFBA e a UNIOESTE/Cascavel, originado no PPGLL. São, portanto, egressas da primeira turma de doutorandas formadas pelo PPGLinC.

c) oito autores, Amanda dos Reis Silva (ME/2014; DO/2018); André Luiz Alves Moreno (ME/2014; DO/2019); Fernanda de Oliveira Cerqueira (ME/2015; DO/2019); Isis Juliana Figueiredo de Barros (ME/2013; DO/2018); Lisana Rodrigues Trindade Sampaio (ME/2013; DO/2018); Mailson dos Santos Lopes (ME/2013; DO/2018); Natival Almeida Simões Neto (ME/2016; DO/2020) e Sebastian Perichon Stanley (ME/2016; DO/2020), são egressos dos cursos de Mestrado e de Doutorado do PPGLinC, Área 1, vinculados a uma das três linhas de pesquisa da área, revelando um processo formativo contínuo e frutífero, uma vez que obtiveram as duas titulações durante a primeira década de funcionamento do Programa. 
d) três autores são egressos de outros Programas de Pós-Graduação: Cristóvão José Santos Júnior (DO/2020) é egresso do PPGLitCult (UFBA); Beatriz Aparecida Alencar (DO/2018) é egressa do Programa de Pós-Graduação em Letras da UFMS (campus Três Lagoas) e Jéssica Carneiro da Silva (ME/2018) é egressa do Programa de Pós-Graduação em Estudos Linguísticos (PPGEL) da UEFS. Os três pesquisadores participam de projetos de pesquisa vinculados ao PPGLinC, o que revela o caráter colaborativo existente entre Programas de PósGraduação do País.

e) uma autora, Vivian Antonino (DO/2012), é egressa da última turma de Doutorado do PPGLL e sua participação demonstra a intrínseca relação formativa que une os dois Programas.

f) alguns autores são egressos do curso de Mestrado do PPGLinC e de outros Programas de Pós-Graduação ${ }^{14}$, já estão atuando como professores na educação básica e/ou em universidades baianas e também estão cursando o Doutorado no PPGLinC, e, como discutido anteriormente, cumprindo o que se almeja com o objetivo quatro do PPGLinC.

g) por fim, participaram como autores ou coautores de trabalhos cinco docentes do PPGLinC, a saber: Denise Chaves de Meneses Scheyerl (ME/1979) e Jacyra Andrade Mota (ME/1980), egressas do primeiro Mestrado em Letras; Edleise Mendes Oliveira Santos (ME/1996), egressa do Mestrado em Letras; Silvana Soares Costa Ribeiro, egressa do Mestrado em Letras (ME/1998) e do Doutorado do PPGLL (DO/2012) e Maria Cristina Vieira de Figueiredo Silva, egressa do PPGLL (ME/2004; DO/2009).

Na próxima seção apresentamos os artigos que compõem o Volume Especial Comemorativo 10 anos do PPGLinC - egressos (nº 68/2020).

14 É importante destacar a oportunidade de formação em nível de Doutorado que o PPGLinC cumpriu até 2019, quando era o único curso de DO sediado no Estado da Bahia. 
Optamos, na organização deste Volume Especial Comemorativo 10 anos do PPGLinC - egressos, por dispor os artigos em ordem cronológica de obtenção do título pelos autores. Como o Programa foi criado em 2010, é natural que os egressos passassem a ser registrados a partir de 2011, mínimo de dois anos para a conclusão dos cursos dos primeiros discentes ingressantes no Mestrado. Como representantes dos egressos de cada ano temos:

Quadro 1: Demonstrativo de artigos que compõem o Volume Especial Comemorativo 10 anos do PPGLinC - egressos - cronologia e distribuição de autores

\begin{tabular}{|c|c|c|c|}
\hline $\begin{array}{l}\text { ano da } \\
\text { defesa }\end{array}$ & $\begin{array}{l}\text { total de } \\
\text { artigos por } \\
\text { ano } \\
\end{array}$ & $\begin{array}{l}\text { nível do egresso no ano da } \\
\text { titulação }\end{array}$ & $\begin{array}{c}\text { número de egressos do } \\
\text { PPGLinC e de outros autores } \\
\text { dos artigos }\end{array}$ \\
\hline 2011 & 1 & 1 de Mestrado & 1 egresso PPGLinC \\
\hline 2012 & 1 & 1 de Mestrado & 1 egresso PPGLinC \\
\hline 2013 & 2 & 2 de Doutorado & $\begin{array}{l}3 \text { egressos PPGLinC } \\
1 \text { egresso PPGLitCult }\end{array}$ \\
\hline 2014 & 4 & 4 de Doutorado & $\begin{array}{c}4 \text { egressos PPGLinC } \\
3 \text { outros autores }\end{array}$ \\
\hline 2016 & 4 & $\begin{array}{c}2 \text { de Mestrado }(2016 / 2018) \\
3 \text { de Doutorado }\end{array}$ & $\begin{array}{c}5 \text { egressos do PPGLinC } \\
2 \text { outros autores }\end{array}$ \\
\hline 2017 & 2 & $\begin{array}{c}1 \text { de Mestrado } \\
1 \text { de Doutorado }\end{array}$ & $\begin{array}{c}2 \text { egressos do PPGLinC } \\
1 \text { outro autor } \\
\end{array}$ \\
\hline 2018 & 5 & 5 egressos de Doutorado & $\begin{array}{c}5 \text { egressos do PPGLinC } \\
1 \text { outro autor } \\
\end{array}$ \\
\hline 2019 & 6 & $\begin{array}{c}3 \text { de Mestrado } \\
5 \text { de Doutorado }\end{array}$ & $\begin{array}{c}8 \text { egressos do PPGLinC } \\
1 \text { outro autor } \\
\end{array}$ \\
\hline 2020 & 3 & 3 de Doutorado & 3 egressos do PPGLinC \\
\hline--- & 1 & --- & 1 outro autor \\
\hline Totais & 29 & $\begin{array}{c}8(\mathrm{ME})+23(\mathrm{DO})= \\
32\end{array}$ & $\begin{array}{c}32(\text { PPGLinC })+9 \text { (outros) }= \\
41\end{array}$ \\
\hline
\end{tabular}

Fonte: elaborado pelos autores 
Embora tenha tido como objetivo principal a divulgação da produção dos egressos, o Volume Especial congregou egressos de outros momentos da trajetória de formação em Pós-Graduação do ILUFBA (cf. seção 2, letra g), tornando-se um número da Revista ELL de valor histórico para o PPGLinC bastante significativo.

Além dos artigos de autoria de ex-alunos do Programa, o Volume Especial Comemorativo 10 anos do PPGLinC - egressos conta com um texto, que inicia o conjunto de textos publicados, intitulado A Pós-Graduação em Letras: ontem e hoje, elaborado pela professora permanente do PPGLinC Denise Chaves de Menezes Scheyerl, no qual demonstra a trajetória da pesquisa empreendida no Instituto de Letras da UFBA com o foco nos caminhos trilhados pelo PPGLinC em uma década de existência.

Como exposto anteriormente, o volume foi organizado em ordem cronológica de obtenção do título pelos egressos, os quais estão dispostos em ordem alfabética. Nos casos em que há egressos de Mestrado e de Doutorado titulados no mesmo ano, informamos primeiro os trabalhos escritos por mestres. Os artigos estão dispostos em três blocos, agregando três décadas cada: (i) 2011 a 2013; (ii) 2014 a $2017^{15}$ e (iii) 2018 a 2020.

Egressa do ME em 2011, Waleska Oliveira Moura, professora do IFBA, reflete acerca do ensino/aprendizagem de Língua Portuguesa diante da diversidade linguístico-cultural nela existente, adotando os pressupostos da Abordagem Intercultural na formação do professor no artigo Educação intercultural e formação de professores de língua portuguesa. Objetiva discutir a formação de leitores no Brasil, considerando também particularidades da rede pública soteropolitana.

Egressa do ME em 2012, Edileide da Silva Reis do Carmo, professora vinculada à educação básica, Secretaria de Educação de Salvador (SEC-SSA), traz o artigo que se intitula A leitura e a biblioteca escolar: implicações à formação de leitores

15 Não há trabalhos referentes a egressos do ano de 2015. 
nos documentos normativos brasileiros (2011-2020) no qual atualiza a discussão sobre leitura e biblioteca escolar, baseando-se em documentos normativos brasileiros ligados à leitura, à literatura, à escrita, ao livro e à biblioteca, elaborados de 2011 a 2020, numa perspectiva crítico-comparativa, apoiada na pesquisa qualitativa e na Linguística Aplicada.

Os dois artigos seguintes são de autoria de três egressos de DO de 2013 e de um coautor egresso do PPGLitCult de 2020.

Clarice Cristina Corbari e Any Lamb Fenner, egressas de DO, atuam na UNIOESTE e apresentam o artigo Atitudes linguísticas em localidades multilíngues no Paraná: resultados de estudos desenvolvidos no PPGLinC que descreve e analisa as atitudes linguísticas de 72 informantes de quatro localidades do oeste paranaense: Guaíra, Marechal Cândido Rondon, Irati e Santo Antônio do Sudoeste. As autoras se pautaram no aparato teórico da Sociolinguística e discutem questões relativas ao contato e identidade linguística dos entrevistados.

José Amarante Santos Sobrinho, docente da UFBA, egresso de DO em 2013 do PPGLinC, e Cristóvão José Santos Júnior, egresso de DO em 2020 do PPGLitCult, apresentam o artigo Rastros do ritmo em testemunhos da tradição manuscrita e impressa em uma composição de Fulgêncio no qual são abordados os testemunhos da tradição manuscrita e impressa e o processo de estabelecimento de uma composição poética do prólogo prosimétrico das Mitologias de Fulgêncio, o Mitógrafo, autor latino tardo-antigo e norte-africano. Ressaltam a relevância do critério métrico para a fixação textual de composições poéticas em textos de tradição politestemunhal e demonstram como certa prática reiterada de leitura contribuiu para o tardio reconhecimento desse escrito fulgenciano como o registro mais antigo de versificação acentual em textos de inspiração não cristã.

Os quatro próximos artigos envolvem egressos do ano de 2014, os quais contam com coautores diversos. 
Pinguela ou ponte? córrego ou riacho? variação semântico-lexical nos dados do Atlas Linguístico do Brasil (ALiB), artigo de autoria de Genivaldo da Conceição Oliveira, egresso do DO, docente da UFRB, traz os resultados da análise das denominações registradas, nos estados da Bahia e do Paraná, no campo semântico acidentes geográficos nas cidades que constituem a rede de pontos do Atlas Linguístico do Brasil (ALiB) nesses dois estados, baseando-se nos princípios teóricos da Dialetologia, Sociolinguística, Lexicologia e Lexicografia.

Percepção e avaliação social das estratégias de representação do acusativo de segunda pessoa em duas cidades baianas, artigo de autoria de Gilce de Souza Almeida, egressa de DO em 2014 e professora da UNEB, e Vívian Antonino, egressa de DO em 2012 (do extinto PPGLL) e professora da UESB, apresenta resultados da pesquisa sociolinguística desenvolvida em duas localidades baianas: Santo Antônio de Jesus e Salvador. As autoras respaldam-se no arcabouço teórico-metodológico da Sociolinguística Variacionista e na Teoria do Poder e Solidariedade para verificar os valores sociais e psicológicos dos informantes no uso das formas te e the na função de objeto direto.

Atitudes linguísticas aos tratamentos o senhorl a senhora e você em Salvador, Bahia, Brasil, artigo elaborado por Sandra Carneiro de Oliveira, docente da UFBA e egressa de DO, e Jacyra Andrade Mota, orientadora de sua tese de Doutorado, também docente da UFBA, revela as diferentes escolhas das formas de tratamento entre os soteropolitanos condicionadas por fatores sociais como sexo e idade, como forma de denotar atitudes que revelam hierarquia e distanciamento entre interlocutores e níveis de formalidade. As autoras conjugam na pesquisa as contribuições de duas vertentes teóricas: a da Sociolinguística Variacionista e da Sociolinguística Interacional.

As construções relativas no português popular de Feira de Santana-BA, artigo de autoria de Silvana Silva de Farias Araújo, docente da UEFS e egressa de DO, e de Jéssica Carneiro da Silva, docente da UNEB, trata, na perspectiva da 
Sociolinguística Variacionista, das estratégias de relativização em amostras de fala do português popular de Feira de Santana comparando com o uso dessas estratégias no português rural afro-brasileiro.

Para a série histórica 2016, quatro artigos de egressos de Doutorado e de Mestrado são apresentados, todos vinculados à Área 1 do PPGLinC.

Iniciamos a apresentação dos quatro trabalhos desse ano pelo artigo de dois egressos do curso de Mestrado do PPGLinC em coautoria com uma pesquisadora doutora egressa de outra IES. Trata-se do artigo de três pesquisadores: Leandro Almeida dos Santos, docente substituto na UNEB, egresso de ME em 2016, Graziele Ferreira da Silva Santos, docente na educação básica (rede privada), egressa de ME em 2018, e Beatriz Aparecida Alencar, docente no IFMS, intitulado Contribuições do Projeto ALiB para a descrição de áreas dialetais: o estilingue visto de Norte a Sul. No artigo, os autores objetivam, com base em estudos de natureza dialetológica desenvolvidos com corpus do Projeto ALiB, apresentar a configuração de áreas linguísticas no País confirmando que o léxico permite delimitar áreas dialetais e que é possível ratificar a proposta de divisão dialetal do Brasil em dois grandes grupos: os falares do Norte e os falares do Sul, conforme propunha Antenor Nascentes.

Dando continuidade, os outros três trabalhos de 2016 são de egressos de Doutorado e um deles tem coautoria com orientador.

Ana Sartori Gandra, docente da UFBA e egressa DO, no artigo Escrita no Brasil quinhentista: uma análise das grafias nos livros da primeira visitação do tribunal da inquisição em Pernambuco, Itamaracá e Paraíba, busca analisar aspectos da escrita, ilustrados através de quadros, em que se apresentam imagens retiradas dos facsimiles dos manuscritos no início da colonização brasileira, tomando como base os livros produzidos durante a Primeira Visitação da Inquisição Portuguesa ao Brasil. 
Lanuza Lima Santos, docente do IFBA (Camaçari/BA) e egressa DO, em Evidências sociolinguísticas sobre os usos do imperativo no interior da Bahia, discute o uso variável do modo imperativo no português popular da Bahia, fundamentada no quadro teórico-metodológico da Sociolinguística Variacionista. Amplia o conhecimento acerca dos falares da Bahia e abre novas perspectivas de investigação acerca das isoglossas do imperativo ao apontar a complexidade da distribuição do fenômeno no Estado.

Maria do Carmo Sá Teles de Araújo Rolo, docente que atua na educação básica, Governo do Estado da Bahia, e Jacyra Andrade Mota, docente UFBA e orientadora da tese, apresentam o artigo "É pouco ['pok], mas é meu": análise comparativa do apagamento das vogais altas finais em localidades da Bahia e de Minas Gerais em que enveredam pelos caminhos da fonética para tratar das vogais altas [i] e [u] em posição átona final, como em por [aw'fas] por [aw'fası] e ['pok] por ['pokv]. O trabalho pautou-se no aporte teórico-metodológico da Sociolinguística Variacionista e da Dialetologia Pluridimensional, considerando aspectos linguísticos e extralinguísticos.

O bloco de texto referente ao ano de 2017 conta com dois artigos: um de mestrando vinculado à Área 1 e em coautoria com pesquisadora doutora titulada pelo PPGLL e outro de uma doutoranda vinculado à Área 2.

Egresso do ME, Angelo de Souza Sampaio, docente da UFBA, e Silvana Soares Costa Ribeiro, docente da UFBA e egressa de DO do PPGLL em 2012, escrevem o artigo intitulado Estudo das unidades semifraseológicas em textos autênticos do francês: as colocações, fruto do diálogo entre orientando e orientadora e que tem foco no corpus de fraseologismos encontrados na coleção de contos Le Petit Nicolas, frequentemente recomendada como leitura paradidática nas aulas de Francês Língua Estrangeira, analisando as sequências fixas presentes no volume 1 da obra. 
Egressa do DO, Patrícia Argolo Rosa, docente da UESC, no artigo $A$ perspectiva intercultural na formação docente: novos desafios, velhas questões, problematiza a perspectiva intercultural trazendo para discussão os novos desafios e as velhas questões para a formação docente. Baseou-se em teóricos da área. Na pesquisa, a autora utilizou três instrumentos para coleta de dados (questionário, entrevistas semiestruturadas e registros etnográficos) além de ter empreendido uma análise de documentos (projeto pedagógico do curso e os programas dos componentes curriculares) referentes aos cursos estudados.

Os cinco trabalhos escritos por egressos de 2018 são todos de ex-discentes do curso de Doutorado, refletem trabalhos desenvolvidos nas três linhas de pesquisa da Área 1 e envolvem diversos níveis de análise da língua.

Do ALiB ao ALiB: o estudo da ditongação diante de -s em diferentes tempos, de autoria de Amanda dos Reis Silva, docente da UFRB e egressa do DO, trata de um fenômeno fonético comum tanto no português brasileiro quanto no português europeu, a ditongação, reunindo, em um único texto, os resultados de suas pesquisas de Mestrado e de Doutorado desenvolvidas com o corpus do Projeto Atlas Linguístico do Brasil. Respaldando-se no aparato teóricometodológico da Sociolinguística, a autora empreende uma detalhada análise acústica dos dados.

Decisões metodológicas inovadoras na análise da expressão de futuro no português brasileiro, escrito por Franciane Rocha, docente da UFRB e egressa do DO, revela o percurso metodológico adotado em sua tese de doutorado que se propõe a expor e justificar as decisões metodológicas que diferenciam essa pesquisa das demais realizadas sobre o tema da variabilidade na expressão do futuro em português brasileiro (PB) a partir da amostra vernácula de Feira de Santana - BA. Os resultados apontam conclusões bastante relevantes quanto ao acerto da mudança paradigmática da análise, contribuindo para um melhor entendimento do fenômeno pesquisado como parte da realidade sociolinguística do PB. 
O (não) uso das preposições dativas e a relexificação de 'para' no português afrobrasileiro, de autoria de Isis Juliana Figueiredo de Barros, docente da UFRB e egressa do ME em 2013 e do DO em 2018, e de sua orientadora, Maria Cristina Figueiredo, docente da UFBA e egressa do PPGLL, ME em 2004 e DO em 2009, busca apresentar os principais resultados da análise sociolinguística a respeito da variação no uso das preposições dativas a e para em comunidades afro-brasileiras (Helvécia, Sapé, Rio de Contas e Cinzento), levando em conta contextos sintáticosemânticos e sociais.

Entre os meandros da construção de estratégias metodológicas: um relato sobre pesquisas desenvolvidas no âmbito da lexicografia histórico-variacional, elaborado por Lisana Rodrigues Trindade Sampaio, também docente da UFRB e egressa do DO, a partir da apresentação das pesquisas realizadas no âmbito da lexicografia histórico-variacional, registra os métodos e as técnicas que têm norteado a sistematização dos itens lexicais patentes na documentação remanescente importante para o conhecimento da constituição histórica da língua portuguesa.

Tipologia e classificação semânticas dos elementos prefixais em perspectiva historicocêntrica, de autoria de Mailson dos Santos Lopes, docente da UFBA e egresso do DO, traz resultados de tese de doutorado indicada para Prêmio CAPES de Teses - Edição 2019 e uma proposta de classificação dos prefixos prototípicos (semantizados), com base na apreciação de dados empíricos do português e na revisitação à literatura morfológica, fundamentando-se na morfologia descritiva, assumindo também princípios da linguística cognitiva.

O conjunto de seis artigos escritos por egressos do ano de 2019 abrange as duas Áreas de pesquisa presentes no PPGLinC. Tratam-se de trabalhos de três egressos de Mestrado e cinco de Doutorado.

André Luiz Alves Moreno, docente da UNEB, egresso de DO, apresenta o artigo Escrita e liberdade no período colonial: o caso da Revolta dos Letrados (1794), que trata da distribuição e do perfil social dos sujeitos que firmaram suas assinaturas 
no âmbito do processo devassatório da Revolta dos Letrados (1794), no Rio de Janeiro. As chamadas devassas de insurreição compõem uma importante fonte de pesquisa sobre a história do país e a história da cultura escrita no Brasil.

Cezar Alexandre Neri Santos, docente da UFAL, egresso de DO, em seu artigo intitulado Motivações botânica e religiosa na toponímia contemporânea em Sergipe, realiza a descrição da toponímia sergipana dos elementos de natureza física e antropocultural. Pautando-se na taxonomia previamente estabelecida por outros estudiosos, o autor verifica a presença de fitotopônimos e topônimos de motivação religiosa hegemonicamente católica, dada a diversidade de santos e santas e de entidades marianas presentes no corpus investigado.

Fernanda de Oliveira Cerqueira, docente da educação básica (rede privada), egressa de ME em 2015 e DO em 2019, e Victor Cavalcanti Mariano, egresso de ME em 2018, docente do IFPB, apresentam o trabalho intitulado Sobre a morfossintaxe da determinação nominal dos DP em português brasileiro que faz o mapeamento dos comportamentos morfossintático e semântico dos sintagmas nominais, em português brasileiro, a fim de identificar um caminho para a composição de traços relevantes para derivação e interpretação dos nominais nessa língua.

Huda da Silva Santiago, docente da UEFS, egressa de DO, em seu artigo Processos e espaços de participação na cultura escrita no sertão baiano (Século XX), problematiza sobre indícios dos processos de difusão da escrita na zona rural do semiárido da Bahia, caracterizando práticas de letramento predominantes, principalmente, em meados do século $X X$.

Lucas Rodrigues Soares Conceição, professor na Brazilink/ICR, Brasil, Sara Oliveira da Cruz, docente substituta do IFBA, ambos egressos do ME em 2019, e Edleise Mendes, docente da UFBA, egressa de ME do Mestrado em Letras em 1996 e orientadora dos trabalhos, refletem sobre a institucionalização da área de português língua estrangeira/segunda língua (PLE-PL2) na UFBA, discutindo 
as características gerais da Licenciatura em PLE e os princípios que orientam a formação de seus professores no artigo intitulado O português língua estrangeira (PLE) / segunda língua (PL2) na UFBA: institucionalização, desafios e prospecções.

Pedro Daniel dos Santos Souza, docente da UNEB e egresso de DO, apresenta em seu artigo intitulado "Na qual se lhes ensine [...] a ler, escrever, econtar": política linguística e escola para índios na Bahia (1758-1834), parte do trabalho desenvolvido em sua tese indicada para Prêmio CAPES de Teses Edição 2020 que discute a atuação dos escrivães das Câmeras das vilas de índios da Bahia setecentista, quanto à obrigação de ensinar a "ler, escrever e contar aos meninos", assim como as reconfigurações demográfico-linguísticas resultantes desse processo, abrindo caminhos de interpretação sobre a construção das vilas de índios e suas implicações linguísticas, por meio do mapeamento do cumprimento das orientações do Diretório quanto à abertura de escolas públicas e à sua abrangência.

O último bloco é dedicado aos artigos de Doutorado elaborados por egressos de 2020 e, como em outros blocos de anos anteriores, contempla trabalhos desenvolvidos nas duas Áreas de pesquisa do PPGLinC.

Gilvan da Costa Santana, docente do IFS e egresso de DO, em Imagem discursiva feminina nas letras do samba-canção de Dolores Duran e do funk de Tati Quebra Barraco, informa resultados da análise da imagem discursiva feminina presente nas letras de música de Dolores Duran (samba-canção dos anos 1950) e de Tati Quebra Barraco (funk dos anos 2000), levando a efeito a propositura de ver o discurso como lugar em que se pode observar a relação entre língua e ideologia, compreendendo como a língua produz sentidos por/para sujeitos.

Natival Almeida Simões Neto, docente substituto na UEFS, realizando Pós-doutorado na Universidade Federal do Rio de Janeiro, e egresso de DO, em A herança semântica na formação de palavras: uma análise de construções morfológicas de línguas românicas, aborda temática desenvolvida em sua tese e, seguindo os 
princípios teóricos da Linguística Cognitiva, analisa como a metáfora, a metonímia, a focalização e a compressão podem atuar na rede de significados de palavras morfologicamente complexas.

Sebastian Perichon Stanley, professor da educação básica e egresso de DO, em El sistema pronominal átono de tercera persona en Paraguay, revela dados de sua tese, em que analisou, do ponto de vista morfossintático, sincrônico, atual e contrastivo, o uso dos pronomes átonos de terceira pessoa nas variedades do espanhol europeu e do paraguaio.

Não poderíamos finalizar esta apresentação sem agradecer aos pareceristas de várias instituições de ensino superior brasileiras que se dispuseram a avaliar artigos, realizando um trabalho voluntário mesmo no contexto adverso e desafiador imposto pela Pandemia de COVID-19. Contribuíram com pareceres cerca de 90 avaliadores. É importante também destacar que um número expressivo de pareceristas cadastrados na Revista ELL declinou do convite. Os pareceristas mostraram-se ressentidos por não poderem avaliar os artigos a eles destinados, sobretudo, por estarem doentes ou com familiares infectados pelo novo coronavírus.

Estendemos os nossos agradecimentos aos Editores da Revista ELL, Juliana Escalier Ludwig Gayer e Felipe Flores Kupske, pela acolhida ao nosso pedido para que se avaliasse a possibilidade de publicação de um número comemorativo dos 10 anos do PPGLinC e, sobretudo, pelo inestimável apoio dado aos organizadores deste Volume Especial em todas as fases de seu processo de constituição.

No cenário de um ano difícil para o povo brasileiro, invadido pela Pandemia de COVID-19, que desafiou o conhecimento científico e mostrou que só a ciência, a pesquisa realizada com rigor, metodologia bem estabelecida e amparada por um lastro solidamente constituído são capazes de reverter a situação imposta pelo novo coronavírus. A Universidade foi chamada para dar 
uma resposta! E assim o fizemos, temos muito a celebrar com o resultado aqui trazido. A capa deste Volume Especial Comemorativo 10 anos do PPGLinC-egressos (n⿳⺈ 68/2020) é de cor verde significando a Esperança, a força e a coragem para enfrentarmos os desafios impostos à sociedade brasileira e mundial em tempos de Pandemia.

É com muita satisfação e alegria que entregamos à comunidade acadêmica o Volume Especial Comemorativo 10 anos do PPGLinC - egressos (n⿳⺈ 68/2020), desejando a todos uma boa leitura.

Salvador, 17 de abril de 2021.

\author{
Silvana Ribeiro (UFBA) \\ Cristina Figueiredo (UFBA) \\ Marcela Paim (UFRPE) \\ Valter Romano (UFSC)
}

\title{
REFERÊNCIAS
}

CAPES. PORTAL PERÍODICOS. Consulta índice H em informativos. Disponível em: https://www-periodicos-capes-gov-

Br.ezl.periodicos.capes.gov.br/index.php?option=com_pnews\&component=Clipping\& view=pnewsclipping\&cid=970\&mn=0\&>. Acesso em: 17 abr. 2021.

CONGRESSO UFBA. Disponível em: <https://congresso2020.ufba.br/>. Acesso em: 17 abr. 2021.

PPGLinC. Relatório de Avaliação do PPGLinC 2019, enviado ao Coleta CAPES (Plataforma Sucupira), Salvador, 2020.

PPGLinC. SITE OFICIAL. Disponível em:< http://www.ppglinc.letras.ufba.br/>. Acesso em: 17 abr. 2021.

SEPESQ. Disponível em: < http://www.sepesq2020.ufba.br/>. Acesso em: 17 abr. 2021.

UFBA EM MOVIMENTO. Disponível em: <https://ufbaemmovimento.ufba.br/>. Acesso em: 17 abr. 2021. 